\title{
Arthroscopic Capsular Release for Frozen Shoulder-Time to Thaw the Delay?
}

\author{
Christopher Munro*, Scott L. Barker, Kapil Kumar \\ Department of Orthopaedics, Woodend General Hospital, Aberdeen, UK \\ Email: *cmunro@nhs.net
}

Received July 9, 2013; revised August 11, 2013; accepted August 20, 2013

Copyright (C) 2013 Christopher Munro et al. This is an open access article distributed under the Creative Commons Attribution License, which permits unrestricted use, distribution, and reproduction in any medium, provided the original work is properly cited.

\begin{abstract}
Introduction: Frozen shoulder is a common condition that affects the working population. Current management regimes are variable nationwide and the evidence base on which to base these decisions is poor. The longevity and severity of symptoms often result in great economic burden, both to health services and in terms of absence from work. Early surgical intervention with arthroscopic capsular release may result in improved symptoms and earlier return to both work and leisure activities. Aims: The aim of our prospective cohort study was to investigate whether early intervention with arthroscopic capsular release resulted in improvement of symptoms and whether this would in turn provide overall economic benefit to society. Methods: Patients diagnosed with frozen shoulder at an elective orthopaedic specialist shoulder clinic were recruited prospectively. Data were gathered by way of questionnaire to ascertain the demographic information of the patient as well as their previous treatment in the primary care setting and absence from work. Initial Oxford Shoulder Score (OSS) was also calculated: Arthroscopic capsular release was then performed and further data gathered at four-week post-operative follow-up. Economic impact of delay to treatment and cost of intervention were calculated using government data from the national tariff which cost different forms of treatment. Statistical analysis was then performed on the results. Results: Twenty five patients were recruited. Mean results were: Age of patients: 53.5 years, duration of symptoms prior to intervention: 35.2 weeks, days absent from work: 31.5, number of previous physiotherapy sessions: 7.2, number of steroid injections: 1.3. Mean pre-operative OSS was 37.4 (range 27 - 58, SD 7.4). Mean post-operative OSS was 15.9 (range 12 - 22, SD 2.3), $\mathrm{P}<0.01$. Mean improvement in OSS was 21.5 (range 12 - 38, SD 7.1). The cost of non-operative treatment per patient including absence from work to the point of surgical intervention was £3954. The overall cost of arthroscopic capsular release per patient was £1861, a difference of £2093. There were no surgical complications. Conclusion: Arthroscopic capsular release improved shoulder function on OSS within four weeks. This is significantly shorter than the natural history of frozen shoulder. The overall cost of arthroscopic capsular release is significantly less than the cost of treating the patients non-operatively up to the point of surgical intervention. Early surgical intervention may improve symptoms quickly and reduce economic burden of the disease. A randomised controlled trial comparing early with late intervention would further elucidate potential benefits.
\end{abstract}

Keywords: Frozen Shoulder; Adhesive Capsulitis; Capsular Release; Arthroscopic; Economics

\section{Introduction}

Frozen Shoulder is a common condition that chiefly affects the working population [1]. Its prevalence is estimated to be $2 \%$ - 5\% [2]. First described by Codman in 1934 [3], the overarching thoughts regarding its aetiology and management were that it was a self limiting condition, the natural history of which could not be altered [4]. Patients were-and still are—advised to endure up to two years of pain and stiffness at the glenohumeral joint with little or no intervention. Theoretically, they

*Corresponding author. were to return to their pre-morbid state after a period of disability.

The aim of our prospective cohort study was to investigate whether early operative intervention, by way of arthroscopic capsular release, resulted in improvement of symptoms and whether this would in turn provide overall economic benefit to the health service and society.

This was also a pilot study to inform us of the viability of proceeding to a randomised controlled study comparing early with delayed surgical intervention.

The theory of spontaneous resolution was re-evaluated following the scientific and clinical work of Bunker et al., 
which likened Frozen Shoulder to Dupytren's Contracture in its pathology, with fibroblasts responsible for a thickening and contracture of the shoulder capsule [5]. His work, along with that of others, including Etoi et al., purported that patients would slowly improve if managed non-operatively, but that rather than making a full recovery, most would have a significant degree of residual dysfunction with or without pain [6,7]. Since this research some has advocated early surgical intervention.

Despite this work, there remains a dearth of high quality research investigating different treatment modalities, particularly randomised controlled trials comparing forms of intervention and no work on the optimum timing of surgical intervention.

\section{Materials and Methods}

Patients diagnosed with primary frozen shoulder at an elective orthopaedic specialist shoulder clinic were recruited prospectively. Inclusion criteria were defined as:

- Decreased movement at glenohumeral joint in all planes-especially external rotation

- Patient aged between 18 and 65 years (working age)

- Symptoms for at least four weeks

- First event Exclusion criteria were defined as:

- Significant history of trauma

- Previous cerebrovascular accident

- Neurological disease

Data was gathered by way of questionnaire to ascertain the demographic information of the patient as well as their previous treatment in the primary care setting. Absence from work was also recorded. Pre-operative Oxford Shoulder Score (OSS) was assessed.

Arthroscopic capsular release was then performed and further data gathered at four week post-operative followup. Economic impact of delay to treatment and cost of intervention was calculated using government data from the national tariff which costs different types of treatment. Statistical analysis was then performed on the results with Mann Whitney U test used to calculate significance of change in OSS.

\section{Results}

Twenty five patients were recruited-14 female and 11 male. Information gathered at initial consultation showed mean age of patients to be 53.47 years with a length of symptoms stretching to an average of eight months (35.16 weeks). All patients had had physiotherapy sessions with an average of 7.15 sessions per patient. All patients had also had intra-articular steroid injection but with a much lower mean of 1.29 injections per patient. All patients had been absent from work, except one pa- tient who did not work. At four week post-operative follow-up 23 of 24 (95.8\%) patients who were employed had returned to their place of work. Mean number of days absent was 31.53 based on a five day working week. This correlates to just over six weeks absence.

OSS data was gathered pre-operatively and postoperatively with change in score calculated for each patient (Table 1). All patients experienced a good reduction in OSS where 60 is the worst score and 12 the best. The lowest change was 12 , the highest 38 , with a mean change of 21.48 (SD 7.12). This was statistically significant with $\mathrm{P}$ value $<0.01$. Post-operative scores were taken four weeks after surgery.

Total Cost of non-operative treatment to the point of surgical intervention was calculated. All non-operative interventions are costed in the NHS tariff for Scotland therefore giving a nominal cost for each physiotherapy session and steroid injection [8]. Government data also supplies the mean cost of one day of absence from work [9]. A mean overall non-operative cost was then calculated using this economic data and the data gathered in Table 2. This was compared with the cost of surgery as per the national tariff [10]. There was a significant difference in these costs with operative surgery being on average £2093.17 cheaper as displayed in Tables $\mathbf{3}$ and $\mathbf{4}$.

There were no surgical complications recorded in any of the twenty five patients. All were treated on a day-case basis.

Table 1. OSS data $(\mathrm{P}<\mathbf{0 . 0 1})$.

\begin{tabular}{cccc}
\hline & Pre-operative & Post-operative & Change \\
\hline Mean & 37.36 & 15.88 & 21.48 \\
Range & $27-58$ & $12-22$ & $12-38$ \\
Standard Deviation & 7.42 & 2.33 & 7.12 \\
\hline
\end{tabular}

Table 2. Demographic data gathered at first consultation.

\begin{tabular}{cccc}
\hline & Mean & Range & $\begin{array}{c}\text { Standard } \\
\text { Deviation }\end{array}$ \\
\hline Age (years) & 53.48 & $32-65$ & 8.46 \\
Length of Symptoms (weeks) & 35.16 & $18-60$ & 9.02 \\
Physiotherapy Session (number) & 7.16 & $3-12$ & 2.36 \\
Steroid Injections (number) & 1.32 & $0-5$ & 1.14 \\
Absence from Work (days) & 31.52 & $18-50$ & 9.00 \\
\hline
\end{tabular}

Table 3. Costs of intervention type and overall cost of nonoperative intervention.

\begin{tabular}{ccc}
\hline Item & Cost (£) & Mean Overall Cost (£) \\
\hline Physiotherapy Session & 126.75 & 906.26 \\
Steroid Injection & 138.51 & 178.68 \\
Day Absent from Work & 91 & 2869.23 \\
Total Non-Operative Cost & N/A & 3954.17 \\
\hline
\end{tabular}


Table 4. Mean overall cost per patient of non-operative versus operative intervention.

\begin{tabular}{cc}
\hline Intervention & Overall Cost (£) \\
\hline Non-operative & 3954.17 \\
Operative & 1861 \\
Difference & 2093.17 \\
\hline
\end{tabular}

\section{Discussion}

It is clear that from the results that surgical intervention by way of arthroscopic capsular release is effective at improving shoulder function in patients with primary frozen shoulder as early as four weeks post-operatively. The change in OSS was statistically significant. The safety of this procedure is also shown favourably with there being no surgical complications.

The impact of surgery in the patients, many of whom have had severe, debilitating symptoms for many months with long absences from work is significant for individual health, as well as having benefits for the health of the population. Surgical intervention is less costly to the NHS, but also to the wider economy, as enabling people to return to work saves costs on sick leave and improves productivity.

Furthermore, a consequence of the current lack of evidence regarding both the most effective management of frozen shoulder as well as the optimal timing of surgical intervention is that management strategies vary widely between and within Orthopaedics and specialist shoulder units throughout the country. Patients are treated based on where they reside and the anecdotal preference of their consultant, rather than on reliable, evidence based surgery.

The burden of disease from frozen shoulder is not insubstantial. That most patients are of working age compounds this. Often patients remain absent from work for many months with an obvious economic, social and psychological cost. Most patients who have surgical intervention have already been symptomatic for many months, with several failed non-operative treatments [11].

The weaknesses of our study are the lack of a control and the small sample size. The need for a larger randomised controlled trial comparing early with delayed surgical intervention is clear. This would require longer term follow-up and a more robust economic analysis. Further studies could compare the effectiveness of different surgical treatment modalities-for example-capsular release, manipulation under anaesthetic and hydrodilatation.

\section{Conclusion}

Early surgical intervention for frozen shoulder by way of arthroscopic capsular release appears to work well and rapidly. Patients with frozen shoulder may return to work and have leisure activities sooner if more are offered in early surgery. The morbidity associated with the surgery appears low. Further research-ideally a randomised controlled trial—is required to ascertain the significance of these early results in a larger cohort with longer follow-up and against a controlled population.

\section{REFERENCES}

[1] K. Walker-Bone, K. T. Palmer, I. Reading, D. Coggon and C. Cooper, "Prevalence and Impact of Musculoskeletal Disorders of the Upper Limb in the General Population,” Arthritis \& Rheumatism, Vol. 51, No. 4, 2004, pp. 642-651. doi:10.1002/art.20535

[2] N. Shah and M. Lewis, "Shoulder Adhesive Capsulitis: Systematic Review of Randomised Trials Using Multiple Corticosteroid Injections," British Journal of General Practice, Vol. 57, No. 541, 2007, pp. 662-667.

[3] R. G. Grey, “The Natural History of 'Idiopathic' Frozen Shoulder,” The Journal of Bone \& Joint Surgery (American Volume), Vol. 60, No. 4, 1978, p. 564.

[4] E. A. Codman, "The Shoulder: Rupture of the Supraspinatus Tendon and Other Lesions in or about the Subacromial Bursa,” Thomas Todd Co., Boston, 1934.

[5] B. Reeves, "The Natural History of the Frozen Shoulder Syndrome," Scandinavian Journal of Rheumatology, Vol. 4, No. 4, 1975, pp. 193-196. doi:10.3109/03009747509165255

[6] M. D. Miller, M. A. Wirth, C. A. Rockwood Jr., "Thawing the Frozen Shoulder: The 'Patient' Patient," Orthopedics, Vol. 19, No. 10, 1996, pp. 849-853.

[7] T. D. Bunker and P. P. Anthony, "The Pathology of Frozen Shoulder: A Dupytren Like Disease," Journal of Bone and Joint Surgery (British Volume), Vol. 77, No. 5, 1995, pp. 677-683.

[8] T. D. Bunker, J. Reilly, K. S. Baird and D. L. Hamblen, "Expression of Growth Factors, Cytokines and Matrix Metalloproteinases in Frozen Shoulder," Journal of Bone and Joint Surgery (British Volume), Vol. 82, No. 5, 2000, pp. 768-773. doi:10.1302/0301-620X.82B5.9888

[9] E. Itoi and S. Tabata, "Range of Motion and Arthrography in the Frozen Shoulder," Journal of Shoulder and Elbow Surgery, Vol. 1, No. 2, 1992, pp. 106-112. doi:10.1016/S1058-2746(09)80128-6

[10] B. Shaffer, J. E. Tibone and R. K. Kerlan, "Frozen Shoulder. A Long Term Follow-Up,” The Journal of Bone \& Joint Surgery (American Volume), Vol. 74, No. 5, 1992, pp. 738-746. doi:10.1136/ard.43.3.361

[11] A. I. Binder, D. Y. Bulgen, B. L. Hazleman and S. Roberts, "Frozen Shoulder: A Long Term Prospective Study," Annals of the Rheumatic Diseases, Vol. 43, No. 3, 1984, pp. 361-364. 